\title{
MODEL PREDIKTOR POTENSI KESULITAN KEUANGAN PERUSAHAAN RETAIL DI INDONESIA
}

\author{
Anandhayu Mahatma Ratri \\ Universitas Merdeka Malang \\ anandhayu.ratri@unmer.ac.id
}

\begin{abstract}
:
The purpose of this study is to analyze and find out the financial distress predicted of retail company in Indonesia using the Altman, Springate, Zmijewski, and Grover models, as well as to analyze and find out the different predictions of the four models in predicting the financial difficulties of Retail companies in Indonesia. This type of research used in this study is a type of quantitative research with a comparative research approach with cross sectional methods. The data analysis tool used is SPSS 25 using the One Way Anova Test. The sample of this research is 22 retail companies which listing in Bursa Efek Indonesia in 2015 - 2017. The results of the study show that result's comparison of the four bankruptcy prediction models, Altman, Springate, Zmijewski, and Grover shows insignificant differences. The total bankrupt companies numbered 3 (three) using the four bankruptcy prediction models for Altman, Springate, Zmijewski, and Grover. The results of the One Way ANOVA different test also showed insignificant results, because the $P$ Value value of 0.350 was greater than 0.05 . Thus, the results of this study can be concluded that the four bankruptcy prediction models of Altman, Springate, Zmijewski, and Grover did not show significant differences.
\end{abstract}

Keywords: Financial Dlstress, Altman, Springate, Zmijewski, Grover

\section{Abstrak:}

Penelitian ini bertujuan untuk menganalisis dan mengetahui hasil prediksi potensi kesulitan keuangan perusahaan Retail di Indonesia menggunakan model Altman, Springate, Zmijewski, dan Grover, serta untuk menganalisis dan mengetahui perbedaan prediksi dari keempat model tersebut dalam memprediksi kesulitan keuangan perusahaan Retail di Indonesia. Jenis penelitian yang digunakan di dalam penelitian ini adalah jenis penelitian kuantitatif dengan pendekatan comparative research atau penelitian perbandingan dengan metode cross sectional. Alat analisis data yang digunakan adalah SPSS 25 dengan menggunakan Uji One Way Anova. Sampel penelitian ini adalah 22 perusahaan sub sektor perdagangan ecer yang listing di Bura Efek Indonesia pada tahun 2015 - 2017. Hasil penelitian menunjukkan bahwa perbandingan hasil perhitungan keempat model prediksi kebangkrutan Altman, Springate, Zmijewski, dan Grover menunjukkan perbedaan yang tidak signifikan. Perusahaan yang dinyatakan bangkrut keseluruhan berjumlah 3 (tiga) menggunakan keempat model prediksi kebangkrutan Altman, Springate, Zmijewski, dan Grover. Hasil dari uji beda ANOVA One Way juga menunjukkan hasil perbedaan yang tidak signifikan, dikarenakan hasil nilai $P$ Value sebesar 0,350 lebih besar dari 0,05 . Dengan demikian, hasil dari penelitian ini dapat disimpulkan bahwa keempat model prediksi kebangkrutan Altman, Springate, Zmijewski, dan Grover tidak menunjukkan perbedaan yang signifikan.

Kata Kunci: Prediksi Kebangkrutan, Altman, Springate, Zmijewski, Grover 


\section{Pendahuluan}

Industri ritel semakin berubah seiring dengan perubahan teknologi, perkembangan dunia serta kebutuhan konsumen. Siap atau tidak, ritel di Indonesia akan menghadapi persaingan yang demikian sengit. Apalagi dengan semakin maraknya ritel asing di Indonesia yang punya kekuatan merek dan dana yang "tak terbatas". Oleh karenanya Retail di Indonesia perlu mewaspadai atau memahami berbagai tren yang akan terjadi pada dunia ritel di masa depan. Berdasarkan data Global Retail Development Index 2017, nilai penjualan ritel Indonesia mencapai US\$ 350 miliar atau sekitar Rp 4,6 kuadriliun. Angka ini jauh di atas nilai penjualan ritel negara-negara di kawasan Asia Tenggara (ASEAN) lainnya. Namun, jika dibandingkan dengan penjualan ritel Tiongkok dan India, Indonesia jauh tertinggal. Penjualan ritel Filipina hanya mencapai US\$ 137 miliar dan Thailand sebesar US\$ 119 miliar, keduanya berada di bawah Indonesia. Sementara penjualan ritel Tiongkok mencapai US\$ 3.128 miliar dan India sebesar US\$ 1.071 miliar. Jumlah populasi Negeri Tirai Bambu yang sangat besar yakni 1,38 miliar jiwa menjadi kunci kekuatan bagi ritel negara tersebut.

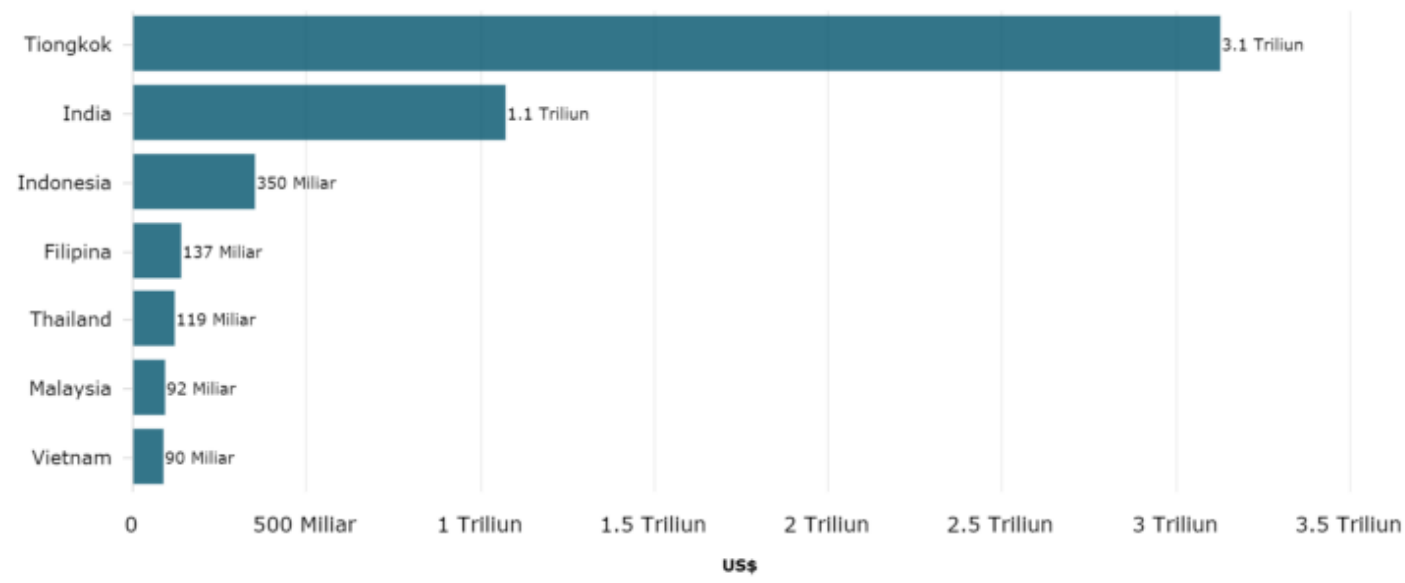

Gambar 1. Nilai Penjualan Ritel di beberapa Negara Asia

Aturan untuk keberadaan pasar modern ada dalam Keputusan Presiden Nomor 112 Tahun 2008 tentang Penataan dan Pembinaan Pasar Tradisional, Pusat Perbelanjaan, dan Toko Modern. Dalam pasal 5 diatur perihal letak pasar modern segala ukuran, dari hipermarket yang terbesar hingga minimarket yang terkecil (Retno, 2010). Kebijakan regulasi pemerintah yang dirasakan persaingan bisnis ritel itu memberi dampak tidak sehat. Akar permasalahan industri ritel di Indonesia adalah sedikitnya keberadaan pasar tradisional menata diri menjadi profesional. Pemda pun memperketat proses perizinan dalam pendirian ritel baru, terutama ritel asing. Pemerintah cenderung mengobral ijin terhadap pemain besar, meskipun sebenarnya pasarnya sudah jenuh. Akibatnya di beberapa kota mulai ada gerai ritel besar yang tutup (Retno, 2010).

Di samping obral ijin terhadap pemain besar, munculnya fenomena belanja online di masyarakat serta ketatnya persaingan juga membuat pertumbuhan penjualan emiten ritel mengalami penurunan dalam lima tahun terakhir. Dapat dilihat pada data dibawah ini, 10 sektor perusahaan dengan nilai kredit bermasalah terbesar, sektor perdagangan besar dan eceran menempati posisi paling tinggi dengan jumlah kredit mencapai 38,1 triliun. 


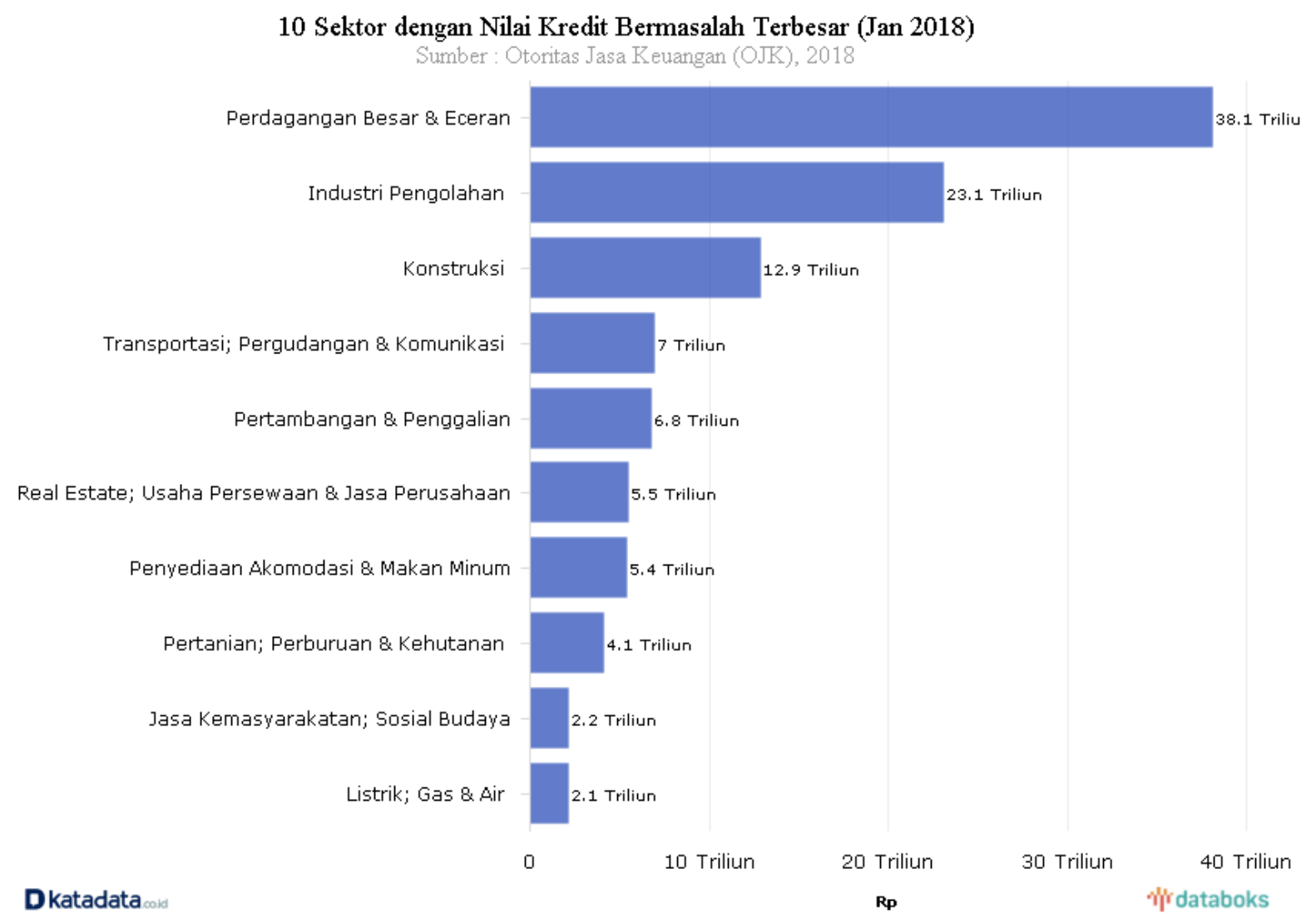

Gambar 2. Grafik 10 Sektor dengan Nilai Kredit Bermasalah Terbesar

Sumber: Otoritas Jasa Keuangan (OJK), 2018

Hal tersebut sudah cukup menggambarkan kondisi finansial yang kurang baik bagi perusahaan dan disarankan agar melakukan analisa lebih lanjut dengan harapan segala kemungkinan terburuk dapat diantisipasi sedini mungkin untuk lebih menjaga dan mengontrol kondisi keuangan perusahaan agar dapat dikelola dengan lebih baik lagi dan terhindar dari kegagalan finansial.

Model sistem peringatan untuk mengantisipasi adanya financial distress perlu untuk dikembangkan, karena model ini dapat digunakan sebagai sarana untuk mengidentifikasikan bahkan memperbaiki kondisi sebelum sampai pada kondisi krisis atau kebangkrutan. Laporan keuangan dapat dijadikan dasar untuk mengukur kesehatan suatu perusahaan melalui rasio-rasio keuangan yang ada (Hanafi, 2004). Kondisi suatu perusahaan dapat diketahui menggunakan beberapa model yang mungkin dapat memprediksi terjadinya kondisi financial distress.

Terdapat penelitian terdahulu yang mencoba untuk melakukan analisis prediksi kebangkrutan atau kesulitan keuangan terhadap perusahaan. Brimantyo, dkk. (2013) mencoba untuk menggunakan salah satu metode prediksi kebangkrutan yaitu z-score untuk mengetahui potensi kebangkrutan perusahaan di sektor telekomunikasi. Hasil penelitian tersebut menunjukkan bahwa terdapat tiga perusahaan yang memiliki kondisi keuangan yang kurang baik sehingga menurut analisis diskriminan altman z-score maka ketiga perusahaan tersebut dinyatakan bangkrut.

Di dalam penelitian ini, peneliti mencoba untuk menggunakan tidak hanya satu model prediktor. Peneliti mengunakan model Altman (z-score), Springate (s-score), Zmijewski ( $x$-score), dan Grover ( $g$-score) di dalam penelitian ini. Ada dua motif dilakukannya penelitian dalam model ramalan kesulitan keuangan. Pertama adalah untuk menguji hubungan antara faktor finansial dan pengukuran kegagalan, yang kedua mengembangkan model bagi peramalan kebangkrutan (Sumarno Zain, 1995). Penelitian yang dilakukan oleh peneliti berkaitan dengan 
motif kedua, yaitu untuk mengembangkan model bagi peramalan kebangkrutan dengan memasukkan fakorfaktor yang memengaruhinya. Hal inilah yang menarik dan mendorong peneliti untuk melakukan penelitian lebih lanjut dengan tujuan untuk mendalami model prediktor potensi kesulitan keuangan pada perusahaan retail di Indonesia.

\section{Metode Penelitian}

Jenis penelitian yang digunakan di dalam penelitian ini adalah jenis penelitian kuantitatif dengan pendekatan comparative research atau penelitian perbandingan dengan metode cross sectional. Penelitian ini mencoba membandingkan potensi financial distress pada Perusahaan retail dengan empat model prediksi kebangkrutan, yaitu Z-score, S-score, X-score, dan G-score. Penelitian dilakukan pada perusahaan sub sektor perdagangan eceran yang terdaftar (listing) di Bursa Efek Indonesia (BEI) periode 2015 - 2017. Alat analisis data yang digunakan adalah SPSS 25 dengan menggunakan Uji One Way Anova. Sampel penelitian ini adalah 22 perusahaan sub sektor perdagangan ecer yang listing di Bura Efek Indonesia pada tahun 2015 - 2017.

\section{Hasil Penelitian}

Berdasarkan hasil perhitungan model Altman, Springate, Zmijewski, dan grover pada perusahaan sub sektor perdagangan eceran yang terdaftar di Bursa Efek Indonesia (BEI), dapat diketahui dari perhitungan keempat model tersebut tidak sama. Perbedaan hasil perhitungan tersebut dapat dilihat dari banyaknya sampel yang sehat dan berpotensi mengalami financial distress berdasarkan analisis menggunakan keempat model analisis kebangkrutan. Banyaknya sampel yang sehat dan berpotensi mengalami financial distress dapat dilihat pada tabel berikut:

Tabel 1. Perbandingan Hasil Empat Model Prediksi Kebangkrutan

\begin{tabular}{|c|c|c|c|c|c|c|}
\hline NO & $\begin{array}{c}\text { NAMA } \\
\text { PERUSAHAAN }\end{array}$ & TAHUN & Z-SCORE & S-SCORE & X-SCORE & G-SCORE \\
\hline \multirow[t]{3}{*}{1} & \multirow[t]{3}{*}{ ACES } & 2015 & SEHAT & SEHAT & SEHAT & SEHAT \\
\hline & & 2016 & SEHAT & SEHAT & SEHAT & SEHAT \\
\hline & & 2017 & SEHAT & SEHAT & SEHAT & SEHAT \\
\hline \multirow[t]{3}{*}{2} & \multirow[t]{3}{*}{ AMRT } & 2015 & SEHAT & SEHAT & SEHAT & SEHAT \\
\hline & & 2016 & GREY AREA & SEHAT & SEHAT & SEHAT \\
\hline & & 2017 & GREY AREA & SEHAT & SEHAT & SEHAT \\
\hline \multirow[t]{3}{*}{3} & \multirow[t]{3}{*}{ CENT } & 2015 & SEHAT & DISTRESS & SEHAT & SEHAT \\
\hline & & 2016 & SEHAT & DISTRESS & SEHAT & SEHAT \\
\hline & & 2017 & GREY AREA & DISTRESS & SEHAT & SEHAT \\
\hline \multirow[t]{3}{*}{4} & \multirow[t]{3}{*}{ CSAP } & 2015 & GREY AREA & SEHAT & SEHAT & SEHAT \\
\hline & & 2016 & GREY AREA & SEHAT & SEHAT & SEHAT \\
\hline & & 2017 & GREY AREA & SEHAT & SEHAT & SEHAT \\
\hline \multirow[t]{3}{*}{5} & \multirow[t]{3}{*}{ ECII } & 2015 & SEHAT & SEHAT & SEHAT & SEHAT \\
\hline & & 2016 & SEHAT & DISTRESS & SEHAT & SEHAT \\
\hline & & 2017 & SEHAT & SEHAT & SEHAT & SEHAT \\
\hline \multirow[t]{3}{*}{6} & \multirow[t]{3}{*}{ ERAA } & 2015 & SEHAT & SEHAT & SEHAT & SEHAT \\
\hline & & 2016 & GREY AREA & SEHAT & SEHAT & SEHAT \\
\hline & & 2017 & GREY AREA & SEHAT & SEHAT & SEHAT \\
\hline \multirow[t]{3}{*}{7} & \multirow[t]{3}{*}{ GLOB } & 2015 & DISTRESS & DISTRESS & DISTRESS & DISTRESS \\
\hline & & 2016 & DISTRESS & DISTRESS & DISTRESS & DISTRESS \\
\hline & & 2017 & DISTRESS & DISTRESS & DISTRESS & DISTRESS \\
\hline \multirow[t]{2}{*}{8} & \multirow[t]{2}{*}{ GOLD } & 2015 & SEHAT & DISTRESS & SEHAT & SEHAT \\
\hline & & 2016 & GREY AREA & DISTRESS & SEHAT & DISTRESS \\
\hline
\end{tabular}




\begin{tabular}{|c|c|c|c|c|c|c|}
\hline NO & $\begin{array}{c}\text { NAMA } \\
\text { PERUSAHAAN }\end{array}$ & TAHUN & Z-SCORE & S-SCORE & X-SCORE & G-SCORE \\
\hline & & 2017 & GREY AREA & DISTRESS & SEHAT & DISTRESS \\
\hline \multirow[t]{3}{*}{9} & \multirow[t]{3}{*}{ HERO } & 2015 & SEHAT & DISTRESS & SEHAT & SEHAT \\
\hline & & 2016 & SEHAT & SEHAT & SEHAT & SEHAT \\
\hline & & 2017 & SEHAT & DISTRESS & SEHAT & SEHAT \\
\hline \multirow[t]{3}{*}{10} & \multirow[t]{3}{*}{ KOIN } & 2015 & GREY AREA & SEHAT & SEHAT & SEHAT \\
\hline & & 2016 & GREY AREA & SEHAT & SEHAT & SEHAT \\
\hline & & 2017 & GREY AREA & SEHAT & SEHAT & SEHAT \\
\hline \multirow[t]{3}{*}{11} & \multirow[t]{3}{*}{ LPPF } & 2015 & SEHAT & SEHAT & SEHAT & SEHAT \\
\hline & & 2016 & SEHAT & SEHAT & SEHAT & SEHAT \\
\hline & & 2017 & SEHAT & SEHAT & SEHAT & SEHAT \\
\hline \multirow[t]{3}{*}{12} & \multirow[t]{3}{*}{ MAPI } & 2015 & GREY AREA & SEHAT & SEHAT & SEHAT \\
\hline & & 2016 & GREY AREA & DISTRESS & SEHAT & SEHAT \\
\hline & & 2017 & GREY AREA & SEHAT & SEHAT & SEHAT \\
\hline \multirow[t]{3}{*}{13} & \multirow[t]{3}{*}{ MIDI } & 2015 & GREY AREA & SEHAT & SEHAT & SEHAT \\
\hline & & 2016 & DISTRESS & SEHAT & SEHAT & SEHAT \\
\hline & & 2017 & DISTRESS & DISTRESS & SEHAT & DISTRESS \\
\hline \multirow[t]{3}{*}{14} & \multirow[t]{3}{*}{ MKNT } & 2015 & SEHAT & SEHAT & SEHAT & SEHAT \\
\hline & & 2016 & SEHAT & SEHAT & SEHAT & SEHAT \\
\hline & & 2017 & SEHAT & SEHAT & SEHAT & SEHAT \\
\hline \multirow[t]{3}{*}{15} & \multirow[t]{3}{*}{ MPPA } & 2015 & SEHAT & SEHAT & SEHAT & SEHAT \\
\hline & & 2016 & SEHAT & SEHAT & SEHAT & SEHAT \\
\hline & & 2017 & DISTRESS & DISTRESS & DISTRESS & DISTRESS \\
\hline \multirow[t]{3}{*}{16} & \multirow[t]{3}{*}{ RALS } & 2015 & SEHAT & SEHAT & SEHAT & SEHAT \\
\hline & & 2016 & SEHAT & SEHAT & SEHAT & SEHAT \\
\hline & & 2017 & SEHAT & SEHAT & SEHAT & SEHAT \\
\hline \multirow[t]{3}{*}{17} & \multirow[t]{3}{*}{ RANC } & 2015 & SEHAT & SEHAT & SEHAT & SEHAT \\
\hline & & 2016 & SEHAT & SEHAT & SEHAT & SEHAT \\
\hline & & 2017 & SEHAT & SEHAT & SEHAT & SEHAT \\
\hline \multirow[t]{3}{*}{18} & \multirow[t]{3}{*}{ RIMO } & 2015 & DISTRESS & DISTRESS & DISTRESS & DISTRESS \\
\hline & & 2016 & DISTRESS & DISTRESS & DISTRESS & DISTRESS \\
\hline & & 2017 & DISTRESS & DISTRESS & SEHAT & DISTRESS \\
\hline \multirow[t]{3}{*}{19} & \multirow[t]{3}{*}{ SKYB } & 2015 & DISTRESS & DISTRESS & SEHAT & SEHAT \\
\hline & & 2016 & SEHAT & SEHAT & SEHAT & DISTRESS \\
\hline & & 2017 & SEHAT & DISTRESS & SEHAT & SEHAT \\
\hline \multirow[t]{3}{*}{20} & \multirow[t]{3}{*}{ SONA } & 2015 & SEHAT & SEHAT & SEHAT & SEHAT \\
\hline & & 2016 & SEHAT & SEHAT & SEHAT & SEHAT \\
\hline & & 2017 & SEHAT & SEHAT & SEHAT & SEHAT \\
\hline \multirow[t]{3}{*}{21} & TELE & 2015 & SEHAT & SEHAT & DISTRESS & SEHAT \\
\hline & & 2016 & SEHAT & SEHAT & DISTRESS & SEHAT \\
\hline & & 2017 & SEHAT & SEHAT & DISTRESS & SEHAT \\
\hline 22 & TRIO & 2015 & DISTRESS & DISTRESS & DISTRESS & DISTRESS \\
\hline
\end{tabular}




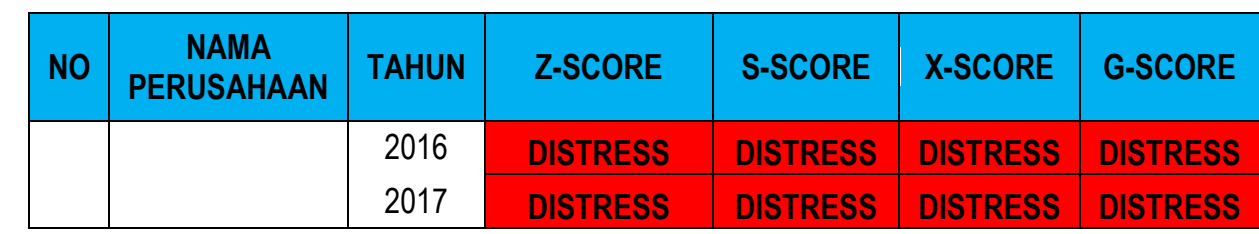

Sumber : Data diolah (2020)

Pada tabel perbandingan hasil empat model prediksi kebangkrutan dapat dilihat perusahaan yang mengalami financial distress menggunakan keempat model prediksi adalah PT. Matahari Putra Prima Tbk pada tahun 2017, PT. Rimo International Lestari Tbk pada tahun 2015 - 2016, dan PT. Trikomsel Oke Tbk pada tahun 2015 - 2017. Perusahaan yang masuk klasifikasi sehat dengan menggunakan keempat model tersebut diantaranya adalah PT. Ace Hardware Indonesia Tbk pada tahun 2015 - 2017, PT. Sumber Alfaria Trijaya Tbk pada tahun 2015, PT. Electronic City Indonesia Tbk pada tahun 2015 dan 2017, PT. Erajaya Swasembada Tbk pada tahun 2015, PT. Hero Supermarket Tbk pada tahun 2016, PT. Matahari Departement Store Tbk pada tahun 2015 - 2017, PT. Mitra Komunikasi Nusantara Tbk pada tahun 2015 - 2017, PT. Matahari Putra Prima pada tahun 2015 - 2016, PT. Ramayana Lestari Sentosa Tbk pada tahun 2015 - 2017, PT. Supra Boga Lestari Tbk pada tahun 2015 - 2017, serta PT. Sona Topas Tourism Industry Tbk pada tahun 2015 - 2017.

Untuk melihat perbedaan hasil pengukuran dari keempat model analisis financial distress, Altman, Springate, Zmijewski, dan Grover, maka akan dilakukan Uji One Way Anova untuk menguji perbedaan hasil skor dari ketiga model tersebut. Berikut hasil Uji ANOVA menggunakan program SPSS:

Tabel 2

Test of Homogeneity of Variances

Levene Statistic df1 df2 Sig.

$40.944 \quad 3260$

.000

Sumber : Data diolah (2020)

Tabel 3

\begin{tabular}{|c|c|c|c|c|}
\hline \multicolumn{5}{|c|}{ ANOVA } \\
\hline & Sum of Squares & $\mathrm{df}$ & Mean Square & Sig. \\
\hline Between Groups & $1.514 \mathrm{E} 10$ & 3 & 5.047E9 1.099 & .350 \\
\hline Within Groups & 1.194E12 & 260 & $4.591 \mathrm{E} 9$ & \\
\hline Total & 1.209E12 & 263 & & \\
\hline
\end{tabular}

Sumber : Data diolah (2020)

Dari tabel hasil Uji ANOVA diatas pada kolom Sig. Didapatkan nilai $P$ ( $P$ value) sebesar 0,350 . Karena hasilnya lebih dari 0,05 maka, dapat disimpulkan bahwa tidak ada perbedaan yang signifikan terhadap keempat model analisis financial distress Altman, Springate, Zmijewski, dan Grover.

\section{Pembahasan}

\section{Perbandingan hasil Prediksi Financial Distress Altman, Springate, Zmijewski, dan Grover}

Hasil analisis dari ketiga metode Altman, Springate, Zmijewski, dan Grover memberikan hasil prediksi yang berbeda-beda namun tidak begitu signifikan, 3 (tiga) perusahaan PT. Matahari Putra Prima Tbk (MPPA), PT. Rimo International Lestari Tbk (RIMO), dan PT. Trikomsel Oke Tbk (TRIO) dinyatakan mengalami financial distress dengan menggunakan keempat model analisis financial distress Altman, Springate, Zmijewski, dan Grover. Perbedaan hasil perhitungan dari setiap model analisis kebangkrutan disebabkan karena perbedaan nilai cut-off dan komponen perhitungan variabel yang berbeda-beda dari masing-masing metode. Dapat dilihat pada tabel 1 yang merupakan hasil perbandingan status prediksi 22 (dua puluh dua) perusahaan menggunakan keempat model analisis kebangkrutan Altman, Springate, Zmijewski, dan Grover. 
Perusahaan dengan kondisi bangkrut dengan jumlah tertinggi didapatkan oleh model Springate (S-Score) sebanyak 11 (sebelas) perusahaan antara lain: PT. Centratama Telekomunikasi Indonesia Tbk (CENT), PT. Electronic City Indonesia Tbk (ECII), PT. Global Teleshop Tbk (GLOB), PT. Golden Retailindo Tbk (GOLD), PT. Hero Supermarket Tbk (HERO), PT. Mitra Adiperkasa Tbk (MAPI), PT. Midi Utama Indonesia Tbk (MIDI), PT. Matahari Putra Prima Tbk (MPPA), PT. Rimo International Lestari Tbk(RIMO), PT. Skybee Tbk (SKYB), serta PT. Trikomsel Oke Tbk (TRIO).

Kondisi perusahaan sehat tertinggi dimiliki oleh metode Grover sebanyak 16 (enam belas) perusahaan, kemudian diurutan kedua dengan metode Springate sebanyak 15 (lima belas) perusahaan yang mendeteksi perusahaan dalam kondisi tidak bangkrut, dan posisi dengan jumlah kondisi perusahaan tidak bangkrut terendah adalah dengan menggunakan metode Altman yang mengindikasi sebanyak 12 (dua belas) perusahaan yang tidak mengalami kebangkrutan di masa mendatang. Terdapat 1 (satu) metode kebangkrutan dengan kondisi grey area dimana pada kondisi tersebut tidak dapat ditentukan perusahaan tersebut pada kondisi bangkrut atau tidak sebanyak 6 (enam) perusahaan.

Hasil penelitian ini memiliki kecenderungan pada hasil penelitian sebelumnya yang dilakukan oleh Oktaviandri, et.al. (2015), pada sektor perusahaan pertanian dengan menggunakan metode Altman, Springate, Ohlson dan Grover dimana terdapat perbedaan dari hasil prediksi tiap model analisis financial distress. Namun, pada penelitian ini perbedaan hasil keempat model Altman, Springate, Zmijewski, dan Grover ketika diterapkan pada perusahaan sub sektor perdagangan eceran hasil perbedaannya tidak begitu signifikan. Pada penelitian sebelumnya, dilakukan perhitungan tingkat akurasi dari keempat metode analisis kebangkrutan, pada penelitian hanya melihat perbedaan dari keempat model Altman, Springate, Zmijewski, dan Grover dengan menggunakan Uji ANOVA One Way.

\section{Perbedaan Prediksi Financial Distress Altman, Springate, Zmijewski, dan Grover}

Untuk melihat ada tidaknya perbedaan yang signifikan dari keempat model prediksi financial distress dalam penelitian ini dilakukan uji beda dengan uji One Way ANOVA. Uji ANOVA digunakan untuk membandingkan dan melihat perbedaan populasi lebih dari 2 mean, pada penelitian ini digunakan uji ANOVA One Way untuk menguji rata-rata pada satu kategori sampel. Bila $P$ value $>0,05$ maka, tidak ada perbedaan yang signifikan terhadap hasil keempat model analisis financial distress Altman, Springate, Zmijewski, dan Grover. Sebaliknya, bila P value $<0,05$ maka, rata-rata yang dibandingkan menunjukkan adanya perbedaan.

Hasil uji beda One Way ANOVA didapatkan nilai Sig. sebesar 0,350 hasil P value lebih besar dari 0,05 , sehingga hasil tersebut menunjukkan tidak adanya perbedaan yang signifikan dari rata-rata hasil skor ketiga model analisis financial distress Altman, Springate Zmijewski, dan Grover. Hal tersebut menunjukkan hasil yang sama dengan perbandingan hasil skor yang telah disajikan pada tabel 1 bahwa tidak ada perbedaan yang signifikan dari hasil perhitungan keempat model analisis financial distress Altman, Springate, Zmijewski, dan Grover.

Hasil penelitian ini mengarah pada penelitian Nikmah dan Sulestari (2014) dimana pada penelitian tersebut dilakukan untuk melihat perbedaan hasil 2 (dua) model prediksi kebangkrutan Ohlson dan Altman, karena yang dibandingkan adalah 2 (dua) metode, uji yang digunakan adalah Paired Sampel T-Test untuk menguji adanya perbedaan rata-rata dari 2 (dua) sampel yang berpasangan. Hasil yang didapatkan dari uji Paired T-Test untuk metode Altman dan Ohlson adalah terdapat perbedaan yang signifikan terhadap 2 (dua) model prediksi kebangkrutan Altman dan Ohlson. Dalam penelitian ini, karena terdiri dari 3 (tiga) metode, maka uji yang digunakan adalah uji ANOVA One Way untuk menguji rata-rata lebih dari 2 (dua) kelompok data dengan satu kategori sampel. Hasil uji ANOVA One Way pada penelitian ini menunjukkan hasil perbedaan yang tidak signifikan, berbeda dengan penelitian sebelumnya yang menggunakan 2 (dua) metode kebangkrutan dengan menggunakan Paired T-Test yang diaplikasikan pada perusahaan sektor perdagangan besar dan kecil menunjukkan perbedaan yang signifikan terhadap hasil analisis metode Altman dan Ohlson. 
Lesmana (2003) mengatakan bahwa kebangkrutan adalah ketidakpastian mengenai kemampuan atas suatu perusahaan untuk melanjutkan kegiatan operasinya jika kondisi keuangan yang dimiliki mengalami penurunan. Darsono dan Ashari, (2005) mengemukakan bahwa kemampuan dalam memprediksi kebangkrutan akan memberikan keuntungan banyak pihak, terutama pada kerditor dan investor. Model prediksi kebangkrutan sudah dikembangkan di beberapa Negara, Altman (1983-1984) melakukan survey model-model yang dikembangkan di Belanda, Kanada, Perancis, Jerman, Swiss, Brazil, Australia, Amerika Serikat, Jepang, Inggris, dan Irlandia yang kemudian nilai tersebut dinyatakan dalam Z-Score.

Springate (1978), menggunakan 19 rasio-rasio keuangan populer yang bisa dipakai untuk memprediksi financial distress. Rasio tersebut dikombinasikan dalam suatu formula akhirnya menemukan 4 rasio yang dapat digunakan dalam memprediksi adanya potensi (indikasi) kebangkrutan perusahaan. Metode Grover diciptakan dengan mendesain dan menilai ulang metode Altman Z-score, Jeffry S. Grover menggunakan sampel sesuai dengan Altman Z-score pada tahun 1968 dengan menambah tiga belas rasio keuangan baru. (Prihantini dan Sari, 2013). Banyak metode kebangkrutan yang dapat digunakan untuk memprediksi kondisi financial perusahaan. Hal tersebut tentu sangat perlu dilakukan, apalagi apabila kondisi kinerja keuangan perusahaan dirasa sudah mulai menurun guna deteksi dini dan sebagai peringatan awal untuk mengatur strategi di masa mendatang agar kondisi terburuk dapat diminimalisir dan dihindarkan. Selain untuk perusahaan, informasi tersebut juga penting untuk kreditor dan investor sebagai bahan pertimbangan pengambilan keputusan sebelum memberikan kredit dan investasi.

\section{Kesimpulan}

Berdasarkan analisis data yang telah dilakukan, maka terdapat dua kesimpulan sebagai berikut:Pertama, perbandingan hasil perhitungan keempat model prediksi kebangkrutan Altman, Springate, Zmijewski, dan Grover menunjukkan perbedaan yang tidak signifikan. Perusahaan yang dinyatakan bangkrut keseluruhan berjumlah 3 (tiga) menggunakan keempat model prediksi kebangkrutan Altman, Springate, Zmijewski, dan Grover. Kedua, Hasil dari uji beda ANOVA One Way juga menunjukkan hasil perbedaan yang tidak signifikan, dikarenakan hasil nilai $P$ Value sebesar 0,350 lebih besar dari 0,05. Dengan demikian, hasil dari penelitian ini dapat disimpulkan bahwa keempat model prediksi kebangkrutan Altman, Springate, Zmijewski, dan Grover tidak menunjukkan perbedaan yang signifikan.

\section{Daftar Pustaka}

Ariani, Desi, Retno. (2010). "Pengaruh Faktor Personality Terhadap Keahlian Karyawan Dalam Menggunakan Komputer (Studi Kasus Pada Karyawan Administrasi Universitas Sebelas Maret Surakarta)", Universitas Muhammdiyah Surakarta.

Brimantyo, H., \& HUSAINI, A. (2013). Penerapan Analisis Altman Z-Score Sebagai Salah Satu Alat Untuk Mengetahui Potensi Kebangkrutan Perusahaan (Pada Perusahaan Telekomunikasi Yang Listing di BEI Periode Tahun 2009-2011). Jurnal Administrasi Bisnis, 1(1), 188-198.

Hanafi, 2004. Manajemen Keuangan. Yogyakarta: BPFE UGM.

Oktaviandri, Annisa., Firli, Anisah., Iradianty, Aldilla. (2017) Analisis Prediksi Kebangkrutan Dengan Model Altman, Springate, Ohlson, dan Grover pada Perusahaan di Sektor Pertanian Bursa Efek Indonesia Periode 2011-2015. Vol. 15, No. 1, Hal: 71-78. Retrieved from Majalah Ilmiah Unikom.

Nikmah dan Sulestari, Dinna Dwi. (2014). Prediksi Financial Distress untuk Perusahaan Besar dan Kecil di Indonesia Perbandingan Ohlson dan Altman. Vol. 4 No. 1, 2014: 36-58.

Rico, Lesmana dan rudi Surjano. (2003). Finansial Performence Analizing. Elek Media Komputindo Kelompok Gramedia: Jakarta

Darsono dan Ashari. (2005). Pedoman Praktis Memahami Laporan Keuangan. Yogyakarta : CV. Andi Offset

E. Altman. 1983. Financial Ratios, Diskriminant Analysis and the Prediction of Corporate Bankruptcy. Journal of Accounting

Springate, Gordon L. V. (1978). Predicting the Possibility of Failure in a Canadian Firm. MBA Research Project Simon Fraser University: unpublished. 
Prihanthini, N. M dan Sari, R. M. (2013). Prediksi Kebangkrutan dengan Model Grover, Altman Z-Score, Springate, dan Zmijewski pada Perusahaan Food and Beverage di Bursa Efek Indonesia. E-Jurnal Akuntansi UniversitasUdayana 5.2 (2013): 417-435. Retrieved from Scholarly Articles Journal. 